\title{
Galectin 3: an extraordinary multifunctional protein in dermatology. Current knowledge and perspectives*
}

\author{
Efstathia Pasmatzi ${ }^{1}$, Christina Papadionysiou ${ }^{1}$, Alexandra Monastirli², George Badavanis ${ }^{2}$, \\ Dionysios Tsambaos ${ }^{2}$
}

DOI: http:/ /dx.doi.org/10.1590/abd1806-4841.20198426

\begin{abstract}
Galectin 3 is a unique $\sim 31 \mathrm{kDa}$ protein that recognizes the N-acetyl-lactosamine structure of several glycoconjugates. It mainly occurs in epithelial and myeloid cells, but is also found in a variety of human cell types. In view of the crucial role played by galectin 3 in the regulation of cellular processes of essential importance and in the pathogenetic mechanisms of diverse disorders, it is not surprising that, particularly in the last three decades, the attention of the scientific community has been increasingly drawn to this extraordinary and multifunctional galectin. In this paper the authors summarize current knowledge on the expression of galectin 3 in normal and diseased human skin, its implications in the pathogenesis, diagnosis and prognosis of cutaneous disorders, and the perspectives of a novel approach to the treatment of the latter using galectin 3 or its inhibitors/antagonists.
\end{abstract}

Keywords: Carbohydrates; Epidermis; Galectin 3; Galectins

\section{INTRODUCTION}

Galectins constitute a family of small and highly conserved soluble proteins that occur in human cells and tissues and in diverse mammals, fungi, nematodes, sponges, insects, and viruses. They reveal a high binding affinity for $\beta$-galactose in glycoconjugates, which varies depending on the structure of the latter and the modifications of their galactose residues, such as sialylation, fucosylation, and sulfation..$^{1,2}$ Among the 17 mammalian galectins identified so far, 12 occur in humans.

Recent accumulating evidence suggests that galectins are involved in a wide variety of significant molecular and cellular processes in both cutaneous and extracutaneous tissues and in the pathogenetic mechanisms of diverse disorders. ${ }^{3}$

The purpose of study paper is to summarize current knowledge on the expression of galectin 3 (Gal 3) in normal and diseased human skin and on its potential functions and implications in the pathogenesis, diagnosis, prognosis, and treatment of cutaneous dis- orders. The overview of the available data is based on the results of an thorough electronic literature research that was conducted on the MEDLINE and SCOPUS databases through April 2018 using various combinations of the primary keyword "Galectins" with relevant terms.

\section{GALECTIN 3}

Gal 3 is a unique $\sim 31 \mathrm{kDa}$ protein that recognizes the N-acetyl-lactosamine structure of several glycoconjugates; in humans it is encoded by LGALS3 gene that is located on chromosome 14 (locus q21-q22).

Gal 3 is widely distributed throughout the body, mainly occurs in epithelial and myeloid cells, but is also found in a variety of cell types in the skin and extracutaneous tissues. ${ }^{4}$ It is secreted by activated macrophages and T- and B-cells, monocytes, Langerhans cells, dendritic cells, neutrophils, basophils, eosinophils, NK cells,

Received 8 May 2018.

Accepted 14 January 2019

* Work conducted at the Department of Dermatology, School of Medicine, Patras University, Rio-Patras, Greece; Center for Dermatologic Diseases, Limassol, Cyprus.

Financial support: None.

Conflict of Interest: None.

Department of Dermatology, School of Medicine, Patras University, Rio-Patras, Greece.

Discipline of Dermatology, Center for Dermatologic Diseases, Limassol, Cyprus.

MAILING AdDREss:

Efstathia Pasmatzi

E-mail: pasmatzi@otenet.gr

C2019 by Anais Brasileiros de Dermatologia 
mast cells and fibroblasts. ${ }^{5-7}$ Gal 3 is mainly located in the cytoplasm where it is synthesized on free ribosomes, but also occurs in the nucleus, the cell surface and in the extracellular space and is secreted from cells by ectocytosis, a new non-classical secretory pathway. Gal 3 reveals a large spectrum of biological functions in normal and pathophysiological conditions and regulates diverse fundamental processes at the molecular and cellular level. ${ }^{8-10}$ (Chart 1).

\section{NORMAL HUMAN SKIN}

In the adult normal human epidermis Gal 3 is found in the cytoplasm of normal keratinocytes with perinuclear enhancement ${ }^{1,11,12}$ in both the basal and the suprabasal layers; in the latter Gal 3 is co-localized with desmosomal proteins. ${ }^{13-17}$ In keratinocyte cultures Gal 3 is upregulated upon enhancement of differentiation. ${ }^{18}$ These findings, taken together with the ability of Gal 3 to bind to laminin and enhance keratinocyte motility, suggest that the expression of this galectin may be related to the differentiation and maturation of keratinocytes. ${ }^{1,19}$

The results of studies on the expression of Gal 3 in normal human melanocytes are conflicting. Mollenhauer et al. ${ }^{16}$ failed to detect any Gal 3 immunoreactivity in melanocytes, whereas Chalupa et al. ${ }^{20}$ detected Gal 3 predominantly in the melanocytic cell body peripherally along the Golgi zone co-localized with melanosome-destined cargo, specifically tyrosinase and tyrosinase-related protein-1 (tyrp-1). Since downregulation of Gal 3 in human melanocytes resulted in reduction of both melanin synthesis and expression/activity of tyrp-1, these authors suggested that Gal 3 may represent a regulatory factor of melanin synthesis affecting the expression of tyrp-1.

In normal human skin, Gal 3 produced and released by the epidermal keratinocytes binds to the surface of Langerhans cells and is then internalized into the Birbeck granules, which participate in the process of antigen presentation. ${ }^{1,21}$ The expression of Gal 3 on the surface of dendritic cells positively correlates with the degree of their maturation ${ }^{22}$ and may be related to their migratory potential. ${ }^{23}$ Indeed, Gal 3-/- bone marrow-derived dendritic cells reveal an impaired migratory response to chemokines in vitro and a reduced migration to

CHART 1. Most significant biological actions of galectin 3 in human tissues

Inhibition of apoptosis

Regulation of extracellular matrix and epithelial cell interactions Modulation of cell migration and adhesion

Involvement in the mechanisms of cell activation and chemoattraction

Significant regulatory role in cell growth and differentiation

Regulation of plasma membrane organization

Regulation of signal transduction

Regulation of immune surveillance

Promotion of angiogenesis in vivo and in vitro

Proinflammatory activity through macrophage activation and migration

Direct binding to pathogens

Induction of fibrosis through increase in fibroblast proliferation and collagen production lymph nodes in vivo, as compared to the gal Gal 3+/+ ones. ${ }^{19}$

In mast cells, Gal 3 expression is found in the cytoplasm (over secretory granules) and the nucleus (heterochromatin). The immunoreactivity for this lectin in cutaneous mast cells is more intense, as compared to that of basophils and mast cells localized in other tissues. Gal 3 is released by these cell types when they are activated and degranulate, a finding that supports a possible role of this galectin in molecular and cellular events associated with mast cells and basophils, particularly in immediate type hypersensitivity reactions. ${ }^{24}$ Moreover, since Gal 3 is a major non-integrin laminin-binding protein, it seems reasonable to suggest that it may be involved in mechanisms underlying the promotion of mast cell adhesion to the basement membranes. ${ }^{25}$ In macrophages, which are the major source of Gal 3, this galectin is overexpressed ${ }^{26}$ and contributes to Fc $\gamma$ R-mediated phagocytosis of erythrocytes, whereas extracellular Gal 3 is known to augment phagocytosis of apoptotic neutrophils by macrophages. ${ }^{27,28}$

Gal 3 immunoreactivity is also found in the sweat glands and the sebaceous glands, whereas in human hair follicles it is located in the cells of the inner root sheath. ${ }^{16}$

\section{CUTANEOUS DISORDERS}

\section{Psoriasis}

Gal 3 expression is lower in the keratinocytes of psoriatic epidermis, as compared to normal epidermis, but it is strong in the Langerhans cells of the psoriatic lesions. ${ }^{29}$ Interestingly, this galectin is also strongly expressed in the dermal capillaries of psoriatic lesions, indicating that both Gal 3 and its glycoligands may be involved in dermal capillary rearrangement and inflammatory cell recruitment. ${ }^{1,19,30}$ The latter finding could be interpreted in terms of Gal 3 induced alterations in the dermal capillary network structure and function in the psoriatic lesions. This hypothesis is also supported by the observation that Gal 3 enhances the formation of capillaries under in vitro conditions. ${ }^{11,19}$

Recently, Shi et al. reported that Gal 3 expression is significantly downregulated in lesional epidermis, but not in the epidermis of the apparently normal skin of psoriatic patients, or in the lesional epidermis of patients with psoriasiform dermatitis, and it became detectable again in the regressive psoriatic lesions. ${ }^{31}$ Furthermore, these authors observed that the deficiency of epidermal Gal 3 was capable of inducing psoriasiform lesions in the skin of Gal 3 -/- mice subsequent to topical imiquimod application and in the skin of these mice after its transplantation onto wildtype mice. These lesions were found to be caused by the spontaneous triggering of psoriatic profile of the keratinocytes through the JNK pathway and the accumulation of neutrophils due to the increased leukocyte recruiting capacity of Gal 3 deficient keratinocytes. Indeed, recombinant Gal 3 was found to suppress in vitro the production of inflammatory molecules such as S100A8/9, CXL1, and CCL20 by the Gal 3 deficient keratinocytes.

The most important finding of this study was the impressive improvement of imiquimod-induced psoriasiform dermatitis in Gal 3-/- mice subsequent to restoration of Gal 3 levels in the skin by intracutaneous injection of recombinant human Gal 3. The exciting results of the study of Shi et al. suggest that Gal 3 deficiency 
may be used as a novel and distinctive diagnostic marker of psoriasis and that administration of recombinant Gal 3 may represent a new and promising approach to the treatment of this keratinization disorder. $^{31}$

Interestingly, an unexpected observation, that is inconsistent with the experimental findings of Shi et al. and the established gal 3 deficiency in psoriasis, was made during phase 2 clinical studies on the efficacy of a Gal 3 inhibitor (GR-MD-02) in the management of nonalcoholic steatohepatitis: a female patient with coexisting plaque psoriasis which was treated with this compound showed a complete remission of her skin lesions (ClinicalTrials.gov Identifier: NCT01899859). ${ }^{31}$

Based on this observation, Ritchie et al. studied the therapeutic efficacy and safety of GR-MD-02 in five adult patients with moderate to severe plaque psoriasis. ${ }^{32}$ Subsequent to a six-month continuous monotherapy with intravenous infusions of this inhibitor (at a dose of $8 \mathrm{mg} / \mathrm{kg}$ every other week), an average $51.9 \%$ reduction of Psoriasis Area and Severity Index (PASI) was seen in the treated patients. One of them revealed a slight rise of PASI score during the six-month follow-up; however, he still revealed a $25 \%$ reduction of pretreatment PASI score. The therapeutic results of GR-MD-02 found in this first clinical trial are rather moderate, as compared to those of other regimens; however, taken together with the absence of any serious adverse drug reactions, they indicate that subsequent to the identification of the optimal therapeutic dose of GR-MD-02 in dose-finding studies, randomized controlled clinical trials on large numbers of psoriatic patients are warranted in order to exactly define the therapeutic efficacy and safety of this Gal 3 inhibitor in the management of chronic plaque psoriasis.

\section{Neoplasms}

\section{Epithelial}

The results of studies performed on the expression of Gal 3 in epithelial cutaneous neoplasms are conflicting. Upregulation of this galectin was reported in head and neck squamous cell carcinomas (SCCs) and in oral carcinomas, ${ }^{33}$ whereas in the most common cutaneous epithelial neoplasms basal cell carcinomas (BCCs) and SCCs Gal 3 expression is clearly reduced or absent. ${ }^{34}$

In circumscribed and infiltrative BCCs, cytoplasmic Gal 3 immunoreactivity was significantly more pronounced than the nuclear immunoreactivity. Moreover, no correlation was detected between BCC tumor size and Gal 3 immunoreactivity. ${ }^{35}$ Since it is unclear whether BCCs originate from basal cells, from the outer root sheaths of the hair follicles, or from both structures, Mollenhauer et al. pointed out that Gal 3 absence in BCCs indicates an important role played by Gal 3 inactivation in the pathogenesis of BCCs. ${ }^{16}$

The findings of comparative studies on Gal 3 expression in normal human epidermis and SCCs are inconsistent. Kapucuoglou et al. ${ }^{35}$ found no differences, whereas Mollenhauer et al. ${ }^{16}$ reported a substantial reduction of Gal 3 levels in SCCs. Interestingly, Kapucuoglou et al. found a significantly higher cytoplasmic immunoreactivity in SCCs, as compared to BCCs, and suggested that this finding may indicate a different biological behavior of these two tumors. ${ }^{35}$ In SCCs, a positive correlation between the intensity of cytoplasmic Gal 3 expression and the tumor size was reported, a finding that is regarded by the authors as indication that Gal 3 may contribute to the mechanisms of tumor enlargement through its anti-apoptotic activity.

Jiang et al. reported that in both benign skin disorders with epidermal hyperplasia and epithelial skin cancers (BCCs and SCCs) there was a significant downregulation of Gal 3 immunoreactivity, which, however, was comparable among the benign disorders and the neoplasms. ${ }^{36}$ They suggested, therefore, that this finding points toward a regulatory pathway independent of the differentiation status of epidermal keratinocytes. Interestingly, since a downregulation of both, Gal 3 and DMBT-1 (protein with mucin-like structure critical for carcinogenesis) is detected in most cutaneous epithelial neoplasms, it has been hypothesized that the interactions of these factors may be implicated in the pathogenetic mechanisms of these tumors. ${ }^{16,36}$

Keratoacanthomas showed staining pattern similar to that seen in SCCs with the least differentiated outer cell layers being invariably negative. ${ }^{12}$ Jiang et al. reported that in keratoacanthomas slightly positive signals for Gal 3 were mainly localized in well-differentiated and well-arranged keratinocytes in lobular structures, whereas no signals were observed in cells with a glassy appearance in deeper areas. ${ }^{36}$

\section{Melanomas}

Absent or minimal expression (predominantly cytoplasmic) of Gal 3 has been reported in the melanocytes in benign melanocytic nevi in both junctional and dermal compartments ${ }^{37}$ and in the intraepidermal component of dysplastic nevi with increasing Gal 3 expression as the lesions progress from dysplastic nevi to melanomas. ${ }^{38}$ Gal 3 expression is stronger in thin primary melanomas, as compared to benign nevi, but is progressively reduced during the development of thick and metastatic melanomas. ${ }^{39,40}$ Prieto et al. reported that in metastatic melanomas there was an increase in both, the levels of Gal 3 and the nuclear/cytoplasmic ratio of Gal 3 expression, as compared to primary melanomas and that nuclear Gal 3 expression correlated well with the prognosis of this tumor. ${ }^{38}$

In melanoma cells Gal 3 expression is mainly localized in the cytoplasm and in some cases also on the cell membranes and nucleus..$^{39,41,42}$ It has been suggested that Gal 3 overexpression in primary cutaneous melanomas may reflect a more aggressive local behavior and metastasizing phenotype; thus Gal 3 may be capable of playing a significant role in the development, progression and prognosis of melanoma. ${ }^{42}$ Additionally, metalloproteinases released by melanoma cells may use Gal 3 as a substrate..$^{39,43}$ Brown et al. suggested that melanoma progression is associated with a depletion of intracellular Gal 3 stores and as a consequence, the decrease in Gal 3 expression may be associated with an increased risk of metastasis and a worse overall prognosis in primary melanoma. ${ }^{39}$

Using a xenograft melanoma model with human melanoma cell lines, Vereecken et al. found that in advanced lesions Gal 3 expression was decreased and inversely correlated with aggressiveness, possibly serving as a trigger of intense proliferation. ${ }^{44}$ Serum Gal 3 concentrations are increased in patients with melanoma, probably due to increased production either by inflammatory cells or by the melanoma cells and are related to serum levels of other pa- 
rameters of inflammation and Gal 3 immunoreactivity in cutaneous metastases. ${ }^{44,45}$

Li et al. reported that nuclear expression of Gal 3 was higher in primary cutaneous melanomas than in primary mucosal melanomas or in melanomas with metastases. ${ }^{40}$ Moreover, since it correlated with necrosis and the age and survival time of patients, these authors suggested that the decrease in nuclear expression of Gal 3 may represent a poor prognostic factor for melanomas.

Pozca et al. reported that elastin-derived peptides generated subsequently to elastin degradation by matrix metalloproteinases increase the invasive potential of melanoma cells and that this effect is predominantly mediated by the cell surface gal 3 receptor. ${ }^{46}$ They suggested, therefore, that a more selective and effective treatment of melanoma could be achieved by inhibition of migration and invasion of melanoma cells using antagonists of gal 3 receptor.

Adoptive T-cell transfer with ex vivo expanded tumor-reactive T-cells generated in mixed lymphocyte melanoma cell cultures is effective in the management of metastatic melanoma. ${ }^{47} \mathrm{Gal} 3$ and indoleamine 2,3-dioxygenase (IDO), both produced by the melanoma cells, as well as the accumulation of $\mathrm{CD}^{+} \mathrm{CD} 25^{+} \mathrm{FoxP} 3 \mathrm{~T}$ cells suppress the expansion of melanoma-reactive $\mathrm{T}$ cells; on the contrary, elimination of melanoma-derived Gal 3 and IDO improve the latter. ${ }^{47}$ These observations may open the way for new and promising approaches to the treatment of metastatic melanoma using Gal 3 inhibitors.

\section{Cutaneous T-cell lymphomas}

Recently, Thode et al. using an organotypic model of cutaneous T-cell lymphoma (CTCL) showed that malignant T-cells markedly stimulate the growth of keratinocytes through secretion of galectins 1 and 3 and cause disorganization of keratinocyte stratification that resembles the early hyperproliferative phase of cutaneous lesions in CTCL. ${ }^{48}$

Mitteldorf et al. comparatively investigated the expression of Gal 3 in the skin lesions of patients with primary cutaneous anaplastic large-cell lymphomas (PCALCL), lymphomatoid papulosis (LYP), and transformed mycosis fungoides with CD30 expression (MF-T). ${ }^{49}$ They found a significantly reduced expression of this galectin in the CD30+ tumor cells of MF-T, as compared to that in CD30+ lymphoproliferative disorders (CD30 LPD), but detected no differences between PCALCL and LYP. In PCALCL Gal 3 was more often localized in the cytoplasm in contrast to LYP, in which an equal distribution in the cytoplasm and the nucleus was more common. These authors suggested that the downregulation of Gal 3 expression in MF-T (in comparison to CD30 LPD) might be used as an additional criterion to differentiate both entities, whereas the different sublocalization of the Gal 3 signal might reflect a different biological function and behavior.

\section{Miscellaneous}

Wounds

EGF-mediated EGFR-ERK signaling is of outmost importance for keratinocyte migration, a decisive prerequisite for re-epithelialization of skin wounds. ${ }^{10}$ Liu et al., using cells isolated from gal 3 deficient mice, demonstrated that in the absence of Gal 3, both keratinocyte migration and skin wound re-epithelialization are impaired..$^{50}$ These authors concluded that the pro-migratory effects of Gal 3 are exerted through regulation of EGFR intracellular trafficking, being carbohydrate independent.

It is known that Gal 3 serves as a receptor for advanced glycation end products (AGEs) leading to their binding and clearance. AGEs are thought to contribute to the defective skin repair in diabetic patients. Using immunohistochemistry, Pepe et al. studied the expression of Gal 3 in tissue derived from chronic wounds and apparently normal skin from the same patient, and found that Gal 3 was strongly expressed in the epidermis and the vasculature of the apparently normal skin and greatly reduced at the wound edge and in the wound bed, in which AGEs labeling was increased. ${ }^{51}$ Based on this inverse correlation between Gal 3 and AGEs, the authors suggested that Gal 3 may protect against AGEs accumulation in wound healing. ${ }^{51}$

In view of Gal 3's implications in cutaneous wound healing, McLeod et al. investigated the efficacy of human recombinant Gal 3 in the treatment of wounds in wild type and diabetic mice. ${ }^{52}$ He found that in vivo topical application of either Gal 3 or gelatin/ gal 3 scaffolds did not affect wound closure, epithelial thickness, re-epithelialization, or macrophage phenotypes in the wound.

\section{Allergic contact and atopic dermatitis}

Gal 3 plays a significant role in the pathogenesis of cutaneous inflammation, since it induces macrophage, lymphoid, and myeloid cell activation, ${ }^{53}$ increases cell adhesion of myeloid cells, ${ }^{54}$ promotes chemoattraction of monocytes and macrophages, ${ }^{55}$ and regulates the response and function of diverse immune cell populations. $^{56}$

Recently, Navarro-Alvarez et al. reported that Gal 3 plasma depletion apheresis in a cutaneous inflammation porcine model through binding immuno-affinity is capable of causing a significant decrease in skin inflammation. Since this method can be also successfully used in human subjects, these authors suggested that it may represent a novel approach to the treatment of cutaneous inflammatory disorders. ${ }^{57}$

It is well known that keratinocytes of human epidermis serve as the primary target of nickel, a major contact allergen. ${ }^{1}$ Interestingly, it has been shown that epidermal exposure to nickel leads to the suppression of Gal 3 in epidermal keratinocytes..$^{58}$ Moreover, intracellular Gal 3 was found to positively regulate allergic contact dermatitis in experimental animals, ${ }^{23}$ possibly through the effects of this galectin on Langerhans cells and other dendritic cells.

Saegusa et al. reported that in patients with atopic dermatitis Gal 3 expression is upregulated in inflammatory cells in the lesional skin but not in their apparently normal skin. ${ }^{59}$

These authors studied the influence of intracellular Gal 3 on the development of allergic inflammatory response in a mouse model of the acute phase of atopic dermatitis subsequent to repeated epicutaneous sensitization with ovalbumin. They detected an upregulation of Gal 3 expression at sites with inflammation induced by the sensitization. In Gal 3 deficient mice the overall inflammatory response, the thickness of the epidermis, the density of eosinophilic and monocytic infiltrate, the serum ovalbumin-specific IgE concen- 
tration, and the intensity of Th2 response were markedly decreased, as compared to Gal 3 wild-type mice.

Moreover, mice to which T-cells were engrafted from Gal 3 deficient mice sensitized with ovalbumin, showed a reduced Th2 response and skin inflammation when compared to the mice which had received T-cells from Gal 3 wild-type animals. The authors, therefore, concluded that Gal 3 is required for the development of inflammatory Th2 response to epicutaneously administered allergens, since in its absence the animals developed a Th1- polarized response. Furthermore, Saegusa et al. found out that the regulatory immune effects of Gal 3 are exerted on both dendritic cells and T-cells and suggested that Gal 3 may play an important role in the acute phase of human atopic dermatitis. ${ }^{10,59}$

These important experimental observations led Galectin Therapeutics Inc. to develop a Gal 3 inhibitor (GR-MD-02), which binds to Gal 3 and blocks its action. The therapeutic efficacy and the safety of this inhibitor were recently evaluated in a phase 1 open label clinical study in three adult patients with recalcitrant atopic dermatitis. GR-MD-02 was intravenously administered at a starting dose of $8 \mathrm{mg} / \mathrm{kg}$ at baseline and then every other week for ten weeks (six infusions). This dose was then increased to $12 \mathrm{mg} / \mathrm{kg}$ (every other week) for additional seven infusions. All three patients revealed improvement in their atopic dermatitis, without any significant side effects, with patient 1 achieving a $64 \%$ reduction in the Eczema Area and Severity Index (EASI) score at 24 weeks, the time of his $13^{\text {th }}$ infusion. This patient has elected to remain on 24 additional weeks of therapy due to his favorable therapeutic response (Press Release, Galectin Therapeutics, Inc. 2017). Currently, an ongoing phase 2 controlled clinical investigations using various dosages of this inhibitor is expected to provide additional information on the efficacy and safety profile of GR-MD-02.

\section{Systemic lupus erythematosus}

Shi et al..$^{60}$ reported that about $78 \%$ of patients with systemic lupus erythematosus (SLE) and lupus-specific lesions revealed serum antibodies against Gal 3, which are capable of directly inducing lupus-like histopathologic skin changes in vivo. The cutaneous vasculitis induced by anti-Gal 3 antibody may be attributed to the function of the Gal 3 protein in mediating endothelial cell morphogenesis and angiogenesis. ${ }^{60}$

It has been recently reported that serum Gal 3 concentrations are upregulated in patients with certain autoimmune disorders and are possibly associated with their activity suggesting the implication of this galectin in the overall inflammatory autoimmune process. ${ }^{60-63}$ Shi et al. investigated the association of serum and cutaneous Gal 3 with lupus erythematosus-specific skin injuries in SLE and other autoimmune disorders. ${ }^{60}$ They found out that serum Gal 3 concentrations were significantly higher in SLE patients, as compared to healthy controls, but did not correlate either with the cutaneous disease activity or the damage score. Additionally, epidermal Gal 3 expression in the lesional skin of SLE patients was reduced, as compared to healthy controls. Based on their findings, these authors concluded that serum Gal 3 is unlikely to play a role in the pathogenesis of cutaneous lesions in SLE, but may be regarded as a potential biomarker for the assessment of SLE activity.

\section{Behçet's disease}

Serum Gal 3 total levels were found to be significantly higher in Behçet's disease (BD) patients, when compared to healthy controls. Interestingly, patients with active BD revealed significantly higher serum Gal 3 levels, as compared to inactive patients and controls and higher Gal 3-binding protein (G3BP) serum levels than the controls. Additionally, serum levels of both Gal 3 and G3BP positively correlated with the BD severity score. ${ }^{64,65}$ These results suggest that serum Gal 3 and G3BP levels may represent new biomarkers indicating the degree of BD clinical activity. It should be noted, however, that their rise in the active phase is not specific for BD, since it is also evident in patients with leukocytoclastic vasculitis.

\section{Systemic sclerosis}

In view of the involvement of Gal 3 in the pathogenetic mechanisms of fibrosis, ${ }^{66}$ serum concentrations of this galectin have been determined in patients with systemic sclerosis and were found to be markedly increased, as compared to healthy controls and correlating with the extent of cutaneous fibrosis. ${ }^{63,67}$ Recently, Faludi $e t$ al. reported that in patients with systemic sclerosis Gal 3 is an independent and reliable biomarker to predict all-cause and cardiovascular-related mortality, and that the serum levels of this galectin are clearly associated with advanced organ fibrosis and inflammation. ${ }^{68}$

\section{CONCLUSIONS}

Galectins are small and highly conserved proteins that are widely distributed in nature, bind to a variety of glycoproteins and glycolipids bearing $\beta$-galactoside residues, and interact with diverse non-glycosylated molecules within the nucleus and the cytoplasm. Gal 3 is a unique $\sim 31 \mathrm{kDa}$ protein that recognizes the N-acetyl-lactosamine structure of several glycoconjugates. Gal 3 regulates diverse fundamental molecular and cellular processes including proliferation, apoptosis, differentiation, immune and inflammatory response, tumor cell growth, migration, invasion, and metastasis.

In normal adult human skin Gal 3 is expressed in the cytoplasm of keratinocytes in the basal and particularly in the suprabasal layers, in hair follicles, sweat and sebaceous glands, in the extracellular matrix of the dermis, in proliferating fibroblasts, Langerhans cells, mast cells, and melanocytes.

Disturbances in the distribution and expression of Gal 3 are associated with a variety of cutaneous disorders in the pathogenetic mechanisms of which this galectin may be involved.

Accumulating experimental and clinical evidence strongly suggests that the introduction and clinical use of inhibitors/antagonists of Gal 3 may open up entirely new avenues in the treatment of cutaneous inflammatory and neoplastic disorders (psoriasis, atopic dermatitis, and melanoma), and may provide a more thorough understanding of and a deep insight into both the mechanisms of their pathogenesis and the processes underlying the biological function of Gal 3. $\square$ 


\section{REFERENCES}

1. Larsen L, Chen HY, Saegusa J, Liu FT. Galectin-3 and the skin. J Dermatol Sci. 2011;64:85-91.

2. Nio-Kobayashi J. Tissue- and cell-specific localization of galectins, $\beta$-galactosebinding animal lectins, and their potential functions in health and disease. Anat Sci Int. 2017:92:25-36.

3. Arthur CM, Cummings RD, Stowell SR. Evaluation of the bactericidal activity of galectins. Methods Mol Biol. 2015;1207:421-30.

4. Shin T. The pleiotropic effects of galectin-3 in neuroinflammation: a review. Acta Histochem. 2013;115:407-11.

5. Funasaka T, Raz A, Nangia-Makker P. Galectin-3 in angiogenesis and metastasis. Glycobiology. 2014;24:886-91

6. Karlsson A, Follin P, Leffler H, Dahlgren C. Galectin-3 activates the NADPH-oxidase in exudated but not peripheral blood neutrophils. Blood. 1998; 91:3430-8.

7. de Oliveira FL, Gatto M, Bassi N, Luisetto R, Ghirardello A, Punzi L, et al. Galectin-3 in autoimmunity and autoimmune diseases. Exp Biol Med (Maywood). 2015:240:1019-28

8. Krześlak A, Lipińska A. Galectin-3 as a multifunctional protein. Cell Mol Biol Lett. 2004:9:305-28.

9. Henderson NC, Sethi T. The regulation of inflammation by galectin-3. Immunol Rev. 2009;230:160-71.

10. Sciacchitano S, Lavra L, Morgante A, Ulivieri A, Magi F, De Francesco GP, et al. Galectin-3: one molecule for an alphabet of diseases, from A to Z. Int J Mol Sci. 2018;19. pii: E379

11. Nangia-Makker P, Honjo $\mathrm{Y}$, Sarvis R, Akahani $\mathrm{S}$, Hogan $\mathrm{V}$, Pienta $\mathrm{KJ}$, et al. Galectin-3 induces endothelial cell morphogenesis and angiogenesis. Am J Pathol. 2000;156:899-909.

12. Konstantinov KN, Shames B, Izuno G. Liu FT. Expression of epsilon BP, a betagalactoside-binding soluble lectin, in normal and neoplastic epidermis. Exp Dermatol. 1994:3:9-16

13. Fowlis D, Colnot C, Ripoche MA, Poirier F. Galectin-3 is expressed in the notochord, developing bones, and skin of the postimplantation mouse embryo. Dev Dyn. 1995;203:241-51.

14. Plzák J, Smetana K Jr, Hrdlicková E, Kodet R, Holíková Z, Liu FT, et al. Expression of galectin-3-reactive ligands in squamous cancer and normal epithelial cells as a marker of differentiation. Int J Oncol. 2001;19:59-64.

15. Holíková Z, Hrdlicková-Cela E, Plzák J, Smetana K Jr, Betka J, Dvoránková B, et al. Defining the glycophenotype of squamous epithelia using plant and mammalian lectins. Differentiation-dependent expression of alpha2,6- and alpha2,3linked $\mathrm{N}$-acetylneuraminic acid in squamous epithelia and carcinomas, and its differential effect on binding of the endogenous lectins galectins- 1 and -3 . APMIS. 2002:110:845-56.

16. Mollenhauer J, Deichmann M, Helmke B, Müller H, Kollender G, Holmskov U, et al. Frequent downregulation of DMBT1 and galectin-3 in epithelial skin cancer. Int J Cancer. 2003;105:149-57.

17. Cada Z1, Smetana K Jr, Lacina L, Plzáková Z, Stork J, Kaltner H, et al. Immunohistochemical fingerprinting of the network of seven adhesion/growthregulatory lectins in human skin and detection of distinct tumour-associated alterations. Folia Biol (Praha). 2009;55:145-52.

18. Sarafian V, Jans R, Poumay Y. Expression of lysosome-associated membrane protein 1 (Lamp-1) and galectins in human keratinocytes is regulated by differentiation. Arch Dermatol Res. 2006;298:73-81.

19. Chen HY, Lo CH, Li CS, Hsu DK, Liu FT. Galectins and cutaneous immunity. Dermatol Sin. 2012;30:121-7.

20. Chalupa A, Koshoffer A, Galan E, Yu L, Liu FT, Boissy RE. Melanocytic galectin-3 is associated with tyrosinase-related protein-1 and pigment biosynthesis. J Invest Dermatol. 2015:135:202-11.

21. Smetana K, Holíková Z, Klubal R, Bovin NV, Dvoránková B, Bartůnková J, et al. Coexpression of binding sites for $A(B)$ histo-blood group trisaccharides with galectin-3 and Lag antigen in human Langerhans cells. J Leukoc Biol. 1999:66:644-9.

22. Bax M, García-Vallejo JJ, Jang-Lee J, North SJ, Gilmartin TJ, Hernández G, et al. Dendritic cell maturation results in pronounced changes in glycan expression affecting recognition by siglecs and galectins. J Immunol. 2007:179:8216-24.

23. Hsu DK, Chen HY, Liu FT. Galectin-3 regulates T-cell functions. Immunol Rev. 2009:230:114-27.

24. Craig SS, Krishnaswamy P, Irani AM, Kepley CL, Liu FT, Schwartz LB. Immunoelectron microscopic localization of galectin-3, an IgE binding protein, in human mast cells and basophils. Anat Rec. 1995;242:211-9.

25. Woo HJ, Shaw LM, Messier JM, Mercurio AM. The major non-integrin laminin binding protein of macrophages is identical to carbohydrate binding protein 35 (Mac-2). J Biol Chem. 1990;265:7097-9.
26. Elliott MJ, Strasser A, Metcalf D. Selective up-regulation of macrophage function in granulocyte-macrophage colony-stimulating factor transgenic mice. J Immunol. 1991:147:2957-63.

27. Sano H, Hsu DK, Apgar JR, Yu L, Sharma BB, Kuwabara I, et al. Critical role of galectin-3 in phagocytosis by macrophages. J Clin Invest. 2003;112:389-97.

28. Karlsson A, Christenson K, Matlak M, Björstad A, Brown KL, Telemo E, et al. Galectin-3 functions as an opsonin and enhances the macrophage clearance of apoptotic neutrophils. Glycobiology. 2009:19:16-20.

29. de la Fuente H, Perez-Gala S, Bonay P, Cruz-Adalia A, Cibrian D, Sanchez-Cuellar $\mathrm{S}$, et al. Psoriasis in humans is associated with down-regulation of galectins in dendritic cells. J Pathol. 2012;228:193-203.

30. Lacina L, Plzáková Z, Smetana K Jr, Stork J, Kaltner H, André S. Glycophenotype of psoriatic skin. Folia Biol (Praha). 2006;52:10-5.

31. Shi Y, He B, Kuchenbecker KM, You L, Xu Z, Mikami I, et al. Inhibition of Wnt-2 and galectin-3 synergistically destabilizes beta-catenin and induces apoptosis in human colorectal cancer cells. Int J Cancer. 2007;121:1175-81.

32. Ritchie S, Neal D, Shlevin H, Allgood A, Traber P. A phase 2a, open-label pilot study of the galectin-3 inhibitor GR-MD-02 for the treatment of moderate-to-severe plaque psoriasis. J Am Acad Dermatol. 2017;77:753-5.

33. Gillenwater A, Xu XC, el-Naggar AK, Clayman GL, Lotan R. Expression of galectins in head and neck squamous cell carcinoma. Head Neck. 1996;18:422-32.

34. Castronovo V, Liu FT, van den Brule FA. Decreased expression of galectin-3 in basal cell carcinoma of the skin. Int J Oncol. 1999;15:67-70.

35. Kapucuoglu N, Basak PY, Bircan S, Sert S, Akkaya VB. Immunohistochemical galectin-3 expression in non-melanoma skin cancers. Pathol Res Pract. 2009;205:97-103

36. Jiang ZX, Tan GZ, Shi ZR, Zhang YP, Han YF, Wang L. Galectin-3 expression in benign and malignant skin diseases with epidermal hyperplasia. Am J Dermatopathol. 2017:39:738-41.

37. Abdou AG, Hammam MA, Farargy SE, Farag AG, El Shafey EN, Farouk S, et al. Diagnostic and prognostic role of galectin 3 expression in cutaneous melanoma. Am J Dermatopathol. 2010:32:809-14.

38. Prieto VG, Mourad-Zeidan AA, Melnikova V, Johnson MM, Lopez A, Diwan AH, et al. Galectin-3 expression is associated with tumor progression and pattern of sun exposure in melanoma. Clin Cancer Res. 2006;12:6709-15.

39. Brown ER, Doig T, Anderson N, Brenn T, Doherty V, Xu Y, et al. Association of galectin-3 expression with melanoma progression and prognosis. Eur $\mathrm{J}$ Cancer. 2012;48:865-74.

40. Li ZW, Wang Y, Xue WC, Si L, Cui CL, Cao DF, et al. Expression and prognostic significance of galectin- 1 and galectin- 3 in benign nevi and melanomas. Zhonghua Bing Li Xue Za Zhi. 2013:42:801-5.

41. Mourad-Zeidan AA, Melnikova VO, Wang H, Raz A, Bar-Eli M. Expression profiling of galectin-3-depleted melanoma cells reveals its major role in melanoma cell plasticity and vasculogenic mimicry. Am J Pathol. 2008;173:1839-52.

42. Buljan $M$, Šitum $M$, Tomas $D$, Milošević $M$, Krušlin B. Prognostic value of galectin-3 in primary cutaneous melanoma. J Eur Acad Dermatol Venereol. 2011;25:1174-81.

43. Ochieng J, Green B, Evans S, James 0, Warfield P. Modulation of the biological functions of galectin-3 by matrix metalloproteinases. Biochim Biophys Acta. 1998:1379:97-106

44. Vereecken P, Zouaoui Boudjeltia K, Debray C, Awada A, Legssyer I, Sales F, et al. High serum galectin-3 in advanced melanoma: preliminary results. Clin Exp Dermatol. 2006;31:105-9.

45. Iurisci I, Tinari N, Natoli C, Angelucci D, Cianchetti E, lacobelli S. Concentrations of galectin-3 in the sera of normal controls and cancer patients. Clin Cancer Res. 2000;6:1389-93

46. Pocza P, Süli-Vargha H, Darvas Z, Falus A. Locally generated VGVAPG and VAPG elastin-derived peptides amplify melanoma invasion via the galectin-3 receptor. In J Cancer 2008:122:1972-80.

47. Melief SM, Visconti VV, Visser M, van Diepen M, Kapiteijn EH, van den Berg JH, et al. Long-term survival and clinical benefit from adoptive T-cell transfer in stage IV melanoma patients is determined by a four-parameter tumor immune signature. Cancer Immunol Res. 2017:5:170-9.

48. Thode C, Woetmann A, Wandall HH, Carlsson MC, Qvortrup K, Kauczok CS, et al. Malignant T-cells secrete galectins and induce epidermal hyperproliferation and disorganized stratification in a skin model of cutaneous T-cell lymphoma. J Invest Dermatol. 2015:135:238-46.

49. Mitteldorf C, Robson A, Tronnier M, Pfaltz MC, Kempf W. Galectin-3 expression in primary cutaneous CD30-positive lymphoproliferative disorders and transformed mycosis fungoides. Dermatology. 2015:231:164-70.

50. Liu W, Hsu DK, Chen HY, Yang RY, Carraway KL 3rd, Isseroff RR, et al. Galectin-3 regulates intracellular trafficking of EGFR through Alix and promotes keratinocyte migration. J Invest Dermatol. 2012;132:2828-37. 
51. Pepe D, Elliott CG, Forbes TL, Hamilton DW. Detection of galectin-3 and localization of advanced glycation end products (AGE) in human chronic skin wounds. Histol Histopathol. 2014;29:251-8.

52. McLeod K, Walker JT, Hamilton DW. Galectin-3 regulation of wound healing and fibrotic processes: insights for chronic skin wound therapeutics. J Cell Commun Signal. 2018;12:281-7.

53. MacKinnon AC, Farnworth SL, Hodkinson PS, Henderson NC, Atkinson KM, Leffler $\mathrm{H}$, et al. Regulation of alternative macrophage activation by galectin-3. $J$ Immunol. 2008:180:2650-8.

54. Balan V, Nangia-Makker P, Schwartz AG, Jung YS, Tait L, Hogan V, et al. Racial disparity in breast cancer and functional germ line mutation in galectin-3 (rs4644): a pilot study. Cancer Res. 2008;68:10045-50.

55. Sano H, Hsu DK, Yu L, Apgar JR, Kuwabara I, Yamanaka T, et al. Human galectin-3 is a novel chemoattractant for monocytes and macrophages. J Immunol 2000;165:2156-64.

56. Chen HY, Sharma BB, Yu L, Zuberi R, Weng IC, Kawakami Y, et al. Role of galectin-3 in mast cell functions: galectin-3-deficient mast cells exhibit impaired mediator release and defective JNK expression. J Immunol. 2006;177:4991-7.

57. Navarro-Alvarez N, Goncalves B, Andrews AR, Wang Z, Wang Z, Harrington E, et al. The effects of galectin-3 depletion apheresis on induced skin inflammation in a porcine model. J Clin Apher. 2018;33:486-93.

58. Gazel A, Rosdy M, Tornier C, De Fraissinette Ade B, Blumenberg M. Transcriptional profiling defines the effects of nickel in human epidermal keratinocytes. J Cell Physiol. 2008;217:686-92

59. Saegusa J, Hsu DK, Liu W, Kuwabara I, Kuwabara Y, Yu L, et al. Galectin-3 protects keratinocytes from UVB-induced apoptosis by enhancing AKT activation and suppressing ERK activation. J Invest Dermatol. 2008;128:2403-11.
60. Shi ZR, Tan GZ, Meng Z, Yu M, Li KW, Yin J, et al. Association of anti-acidic ribosomal protein $\mathrm{P} 0$ and anti-galectin 3 antibodies with the development of skin lesions in systemic lupus erythematosus. Arthritis Rheumatol. 2015;67:193-203.

61. Lim Y, Lee DY, Lee S, Park SY, Kim J, Cho B, et al. Identification of autoantibodies associated with systemic lupus erythematosus. Biochem Biophys Res Commun. 2002;295:119-24.

62. Kang EH, Moon KC, Lee EY, Lee YJ, Lee EB, Ahn C, et al. Renal expression of galectin-3 in systemic lupus erythematosus patients with nephritis. Lupus. 2009;18:22-8

63. Koca SS, Akbas F, Ozgen M, Yolbas S, Ilhan N, Gundogdu B, et al. Serum galectin-3 level in systemic sclerosis. Clin Rheumatol. 2014;33:215-20.

64. Lee YJ, Kang SW, Song JK, Park JJ, Bae YD, Lee EY, et al. Serum galectin-3 and galectin-3 binding protein levels in Behçet's disease and their association with disease activity. Clin Exp Rheumatol. 2007;25(Suppl 45):S41-5.

65. Özden MG, Caycı YT, Tekin H, Çoban AY, Aydın F, Sentürk N, et al. Serum galectin-3 levels in patients with Behçet's disease: association with disease activity over a long-term follow-up. J Eur Acad Dermatol Venereol. 2011;25:1168-73.

66. Li Y1, Yu L, Wu X. Galectin-3 expression in peripheral blood mononuclear cells of chronic hepatitis B patients treated with pegylated interferon alpha-2a. Zhonghua Gan Zang Bing Za Zhi. 2014:22:336-9.

67. Taniguchi T, Asano Y, Akamata K, Noda S, Masui Y, Yamada D, et al. Serum levels of galectin-3: possible association with fibrosis, aberrant angiogenesis, and immune activation in patients with systemic sclerosis. J Rheumatol. 2012;39:539-44.

68. Faludi R, Nagy G, Tőkés-Füzesi M, Kovács K, Czirják L, Komócsi A. Galectin-3 is an independent predictor of survival in systemic sclerosis. Int $\mathrm{J}$ Cardiol. 2017;233:118-24.

\section{AUTHORS' CONTRIBUTIONS}

$\begin{array}{lll}\text { Efstathia Pasmatzi } & \text { (iD) ORCID } 0000-0003-0846-1752\end{array}$

Approval of the final version of the manuscript; Conception and planning of the study; Elaboration and writing of the manuscript; Obtaining, analyzing and interpreting the data; Effective participation in research orientation; Critical review of the manuscript
Christina Papadionysiou
(iD) ORCID
0000-0002-1962-6615

Elaboration and writing of the manuscript; Obtaining, analyzing and interpreting the data
Alexandra Monastirli
(iD) ORCID
0000-0003-4525-6766

Approval of the final version of the manuscript; Elaboration and writing of the manuscript; Obtaining, analyzing and interpreting the data; Effective participation in research orientation; Critical review of the literature; Critical review of the manuscript

George Badavanis

$$
\text { (iD) ORCID 0000-0002-9125-1280 }
$$

Approval of the final version of the manuscript; Elaboration and writing of the manuscript; Obtaining, analyzing and interpreting the data; Critical review of the literature; Critical review of the manuscript

Dionysios Tsambao

(iD) ORCID 0000-0003-1435-8030

Approval of the final version of the manuscript; Conception and planning of the study; Elaboration and writing of the manuscript; Obtaining, analyzing and interpreting the data; Effective participation in research orientation; Critical review of the literature; Critical review of the manuscript

How to cite this article: Pasmatzi E, Papadionysiou C, Monastirli A, Badavanis G, Tsambaos D. Galectin 3: an extraordinary multifunctional protein in dermatology. Current knowledge and perspectives. An Bras Dermatol. 2019;94(3):358-54. 